\title{
Review
}

\section{Early gastric cancer in Europe}

Early gastric cancer (EGC) was first defined in 1962 by the Japanese Society of Gastroenterological Endoscopy as adenocarcinoma confined to the mucosa or submucosa irrespective of lymph node involvement. ${ }^{1}$ The need for such a definition was based on the observation that gastric cancer of this type had a favourable prognosis. Indeed, this had been recognised as early as 1938 by Saeki who reported that patients who had gastric cancer confined to the submucosa had a five year survival in excess of $90 \%{ }^{2}$

Since this classification was devised there has been enormous interest in EGC. Five year survival rates of greater than $90 \%$ have repeatedly been reported in Japan, and more recently, in some centres in the West. As a consequence, screening of the asymptomatic population for EGC has been implemented in Japan, Chile ${ }^{3}$ and Venezuela. ${ }^{4}$ In Europe, and elsewhere, screening has targeted high risk groups, while others have advocated a low threshold for the investigation of dyspepsia. Despite enormous costs, little prospective evidence exists for the ability of such programmes to reduce mortality from gastric cancer.

It continues to be debated, however, whether gastric cancer, and in particular EGC, behaves differently in Japan and the West. This is because Japanese surgeons have, at least until recently, reported better survival rates than their Western counterparts. A variety of reasons for this discrepancy has been offered, including differences in operative technique, population characteristics, and the natural history of the disease.

In this paper we review the European and Western experience of EGC and compare this with the Japanese. A Medline literature search looking for articles on EGC from 1971 to 1996 was performed. All such papers were scrutinised for additional relevant references. Data were tabulated and, whenever possible, this is depicted graphically. In some cases, figures were calculated from data quoted in the text. Clinical features, histopathology, prognostic factors, and survival rates of EGC are all examined, as well as differences between EGC and advanced gastric cancer (AGC).

In total, 72 EGC case series were reviewed. From Europe, there were 30 papers, 10 of which were from Italy. The remainder were from the UK (eight papers), Germany (three), Netherlands (two), Portugal (two), Switzerland, Sweden, Austria, Spain, and France (one each).$^{5-34}$ Further papers were also reviewed from the USA (six), Canada, Brazil, and Australia (one each).$^{35-43}$ From Japan there was a total of 32 papers, ${ }^{4-75}$ and from Korea there was one. ${ }^{76}$ The number of patients in each case series was highly variable. In the European literature it ranged from 11 patients to $271,{ }^{15}{ }^{30}$ whereas in Japan numbers were much higher, up to $17212 .{ }^{47}$ These differences reflect both the higher incidence of gastric cancer in Japan and the determined efforts of the Japanese to combat this disease over the past three decades, resulting in large centres of excellence dedicated to the management of cancer.

\section{Incidence of EGC}

The majority of Western series report the incidence of EGC to be $10-20 \%$ of resected cancers. When all cases (including palliative surgery and patients unsuitable for surgery) are considered, the incidence falls to around $10 \%$.
This, however, is probably an overestimation of the incidence in the community, as these data are almost universally taken from surgical cohorts. When pathological records are examined, the incidence falls further: Ballantyne et al, for instance, report an incidence of EGC in 3.9\% of pathological specimens in the Nottingham General and University Hospitals between 1978 and $1985 .{ }^{18}$ Even this, however, does not take into account cases first reported on death certificates. None the less, the incidence of EGC is increasing in many centres in Europe, reflecting the increased use of gastroscopy, ${ }^{19}$ although not yet approaching the high levels found in Japan.

The Japanese national records show that the percentage of early cancers among resected cases was $40 \%$ in 1985 with a gradual increase in detection rates throughout the country over the preceding 20 years, ${ }^{57}$ whereas in the Cancer Institute of Tokyo the percentage of EGC overtook advanced cancers in $1990 .^{58}$ Again, this is probably an overestimation of the true incidence of EGC in the community. It is none the less clear that EGC is detected considerably more frequently in Japan than in Europe. The reason for this discrepancy is almost certainly the mass screening of the asymptomatic population introduced in 1957, though, as in Europe, the upward trend is closely paralleled by advances in diagnostic technology.

\section{Histopathology}

MACROSCOPIC APPEARANCE

The most widely used classification of EGC is based upon the macroscopic appearance of the tumour (fig 1). EGC is divided into tumours that are protruded (I), superficial (II), and excavated (III). ${ }^{1}$ Type II is further subdivided into elevated (IIa), flat (IIb), and depressed (IIc). Generally, the elevation of type IIa is less than twice the thickness of the adjacent mucosa, whereas in type IIb no elevation or depression can be seen, and in type IIc the depression is only erosion. ${ }^{51}$ Combinations of the five lesions are common, (for instance, a shallow depression (IIc) with a central excavation (III) is classified as type IIc + III).
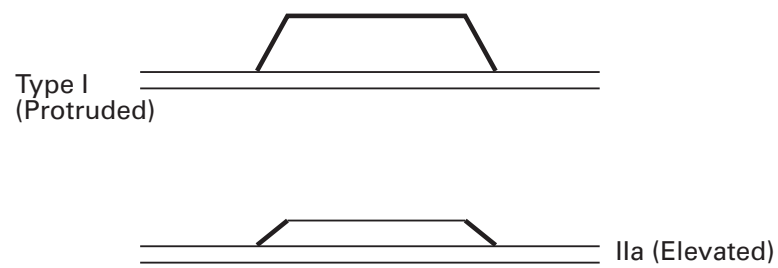

Type II $=$ Ilb (Flat) (Superficial)
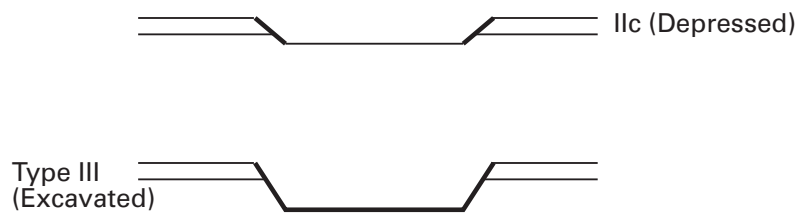

Figure 1: Macroscopic classification of early gastric cancer according to the fapanese Research Society for gastric cancer. 
On the whole, the majority of EGC contain a depressed or ulcerated component with types IIc or III, or both, present in greater than $60 \%$ (fig 2). This is true for both Western and Japanese series. The remainder are mainly elevated, with only a very small number of flat lesions (type IIb) being identified. This no doubt reflects not only the fact that ulcerated lesions are easier to detect, but also that a large number of EGC ulcerate as part of their natural history, an observation first made by Sakita et al, who proposed the "life cycle of the malignant ulcer" ${ }^{77}$ in which there is ulceration and healing, followed by re-ulceration. When flat lesions are detected, however, they are characterised simply by a reddening or pallor of the mucosa. They are usually of minute or small size, and limited to mucosal invasion, suggesting that they are at an early stage in their natural history. ${ }^{70} 71$

\section{SIZE}

The size of EGC varies greatly, ranging from less than $0.5 \mathrm{~cm}$ to $7.0 \mathrm{~cm} .{ }^{6}$ Mean size is reported between $1.7 \mathrm{~cm}$ and $3.0 \mathrm{~cm}$ in Europe and the USA. ${ }^{63536}$ With advancing diagnostic techniques, the proportion of smaller sized lesions is increasing. This is especially true in Japan. ${ }^{44} 4748578$ Xuan et al reviewed 2846 cases of EGC in Japan, and found the frequency of lesions less than $3 \mathrm{~cm}$ increased from 28 to $56 \%$ between 1962 and $1987 .{ }^{48}$

Lesions with a maximum diameter of $5 \mathrm{~mm}$ or less are classified as minute, and those with a diameter of between 6 and $10 \mathrm{~mm}$ as small. These lesions tend to be flat (type IIb) and histologically well differentiated. ${ }^{70}$ Fukutomi and Sakita report that minute lesions accounted for $2.9 \%$ of EGC in 1972 and $4.2 \%$ in 1980, and small lesions for $6.8 \%$ in 1972 and $10.1 \%$ in $1980 .{ }^{47}$ However, in a recent report from Italy, minute lesions accounted for $12 \%$ and small lesions for $23 \%$ of EGC, ${ }^{5}$ whereas Chia et al (Australia) report $21 \%$ small or minute lesions. ${ }^{43}$ Thus, it would seem that there is no great difference in the size of lesions detected on separate continents.
MICROSCOPIC APPEARANCE

Depth of invasion

The definition of EGC allows for invasion only as far as the submucosa, without penetration through the muscularis propria. However, EGC can be divided into those that invade the mucosa only, and those that penetrate the muscularis mucosa to the submucosa. Figure 3 shows the proportion of each type. Although there is wider variation between the smaller Western series, the division is generally around $50 \%$ for both mucosal and submucosal invasion in both Japan and Europe.

Depth of invasion may be predicted by macroscopic type, with polypoid and ulcerated/eroded lesions having deeper invasion than flat lesions. Fukutomi and Sakita reported 17212 cases of EGC from Japan; the ratio of mucosal to submucosal invasion was 6.9 and 2.1, respectively, for types IIb and IIa, compared with a ratio of 1.03, 0.97 and 0.45 for types I, III and IIa + IIc, respectively. ${ }^{47}$

\section{Histological diagnosis}

A helpful pathological classification for gastric cancer was described by Lauren in $1965 .{ }^{79}$ Tumours are divided into those with gland formation (intestinal type) and those without glandular characteristics (diffuse type). Intestinal type occurs more commonly in older patients in areas with a high incidence of gastric cancer, whereas diffuse type has a constant rate worldwide and occurs in a younger age group. This classification is in widespread use in the West. In EGC intestinal type predominates, accounting for more than half of the patients in 16 of 18 reports, and more than $70 \%$ in seven of the 18 (fig 4 ).

Comparison with the Japanese experience is difficult as the Lauren classification is not frequently quoted. Instead, tumours are classified according to the Japanese Research Society Committee ${ }^{80}$ and are divided into papillary, tubular/well differentiated, and tubular/moderately differ-

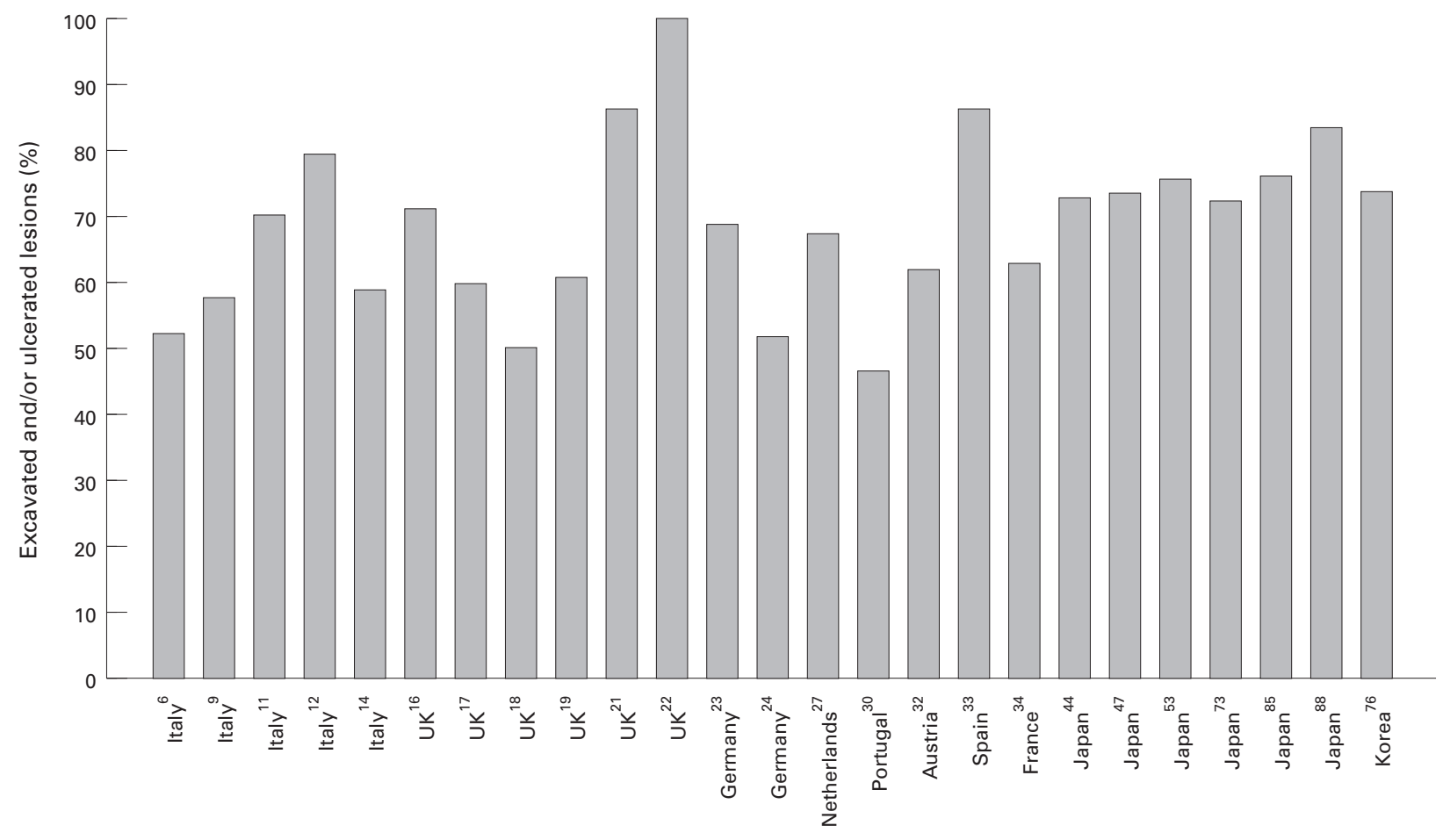

Case series: country and reference

Figure 2: Macroscopic classification of early gastric cancer: per cent of lesions that are depressed or excavated, or a combination of the two (IIc, III, IIc + III). 


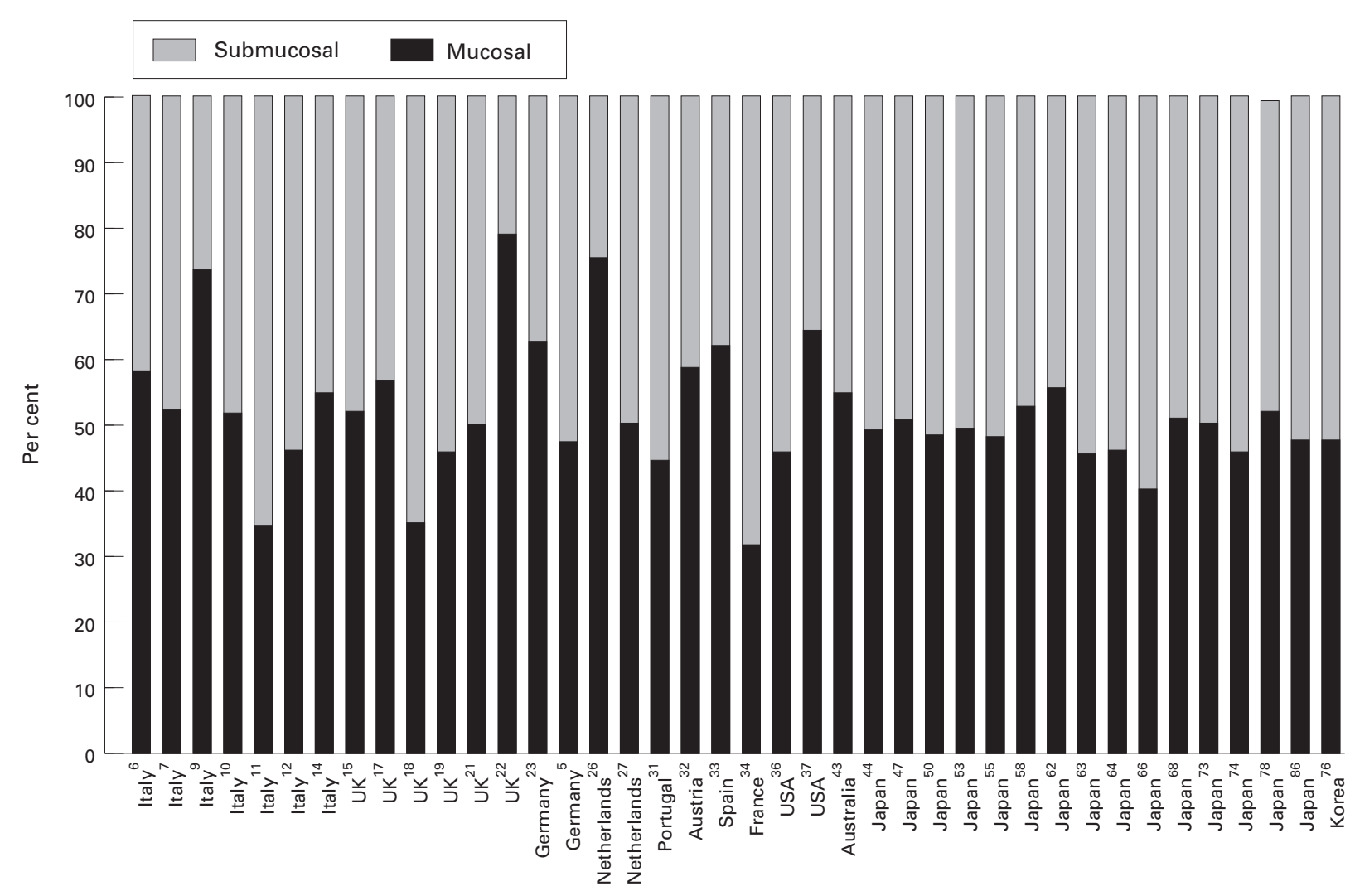

Case series: country and reference

Figure 3: Early gastric cancer and depth of invasion: per cent of lesions that have invaded mucosa alone or have invaded into the submucosa.

entiated adenocarcinoma (which together are considered well differentiated, and correspond to intestinal type), poorly differentiated and signet ring adenocarcinoma (which together correspond to poorly differentiated or diffuse cancer), and mucinous adenocarcinoma. Taken together, differentiated tumours account for around $60 \%$ and undifferentiated for $40 \%$ (table 1). ${ }^{4450535556}$ This compares closely with the Western experience.

It has been reported that the degree of differentiation is closely related to depth of invasion for gastric cancer, with poorer differentiation evident in submucosal and advanced cancers than mucosal lesions. ${ }^{104150}$ This requires confirmation (indeed Eckardt et al report very similar degrees of differentiation between $\mathrm{EGC}$ and $\mathrm{AGC}^{23}$ ), but suggests that either poorly differentiated tumours are more aggressive, or that tumours undergo transformation to a less differentiated type as growth progresses.

It is also worthy of note that there may be some discrepancy in the reporting of degree of differentiation, and even between the classification of benign and malignant disease. Fujii et al reported 30 cases of EGC from Japan defined as tub 0, that is, very well differentiated tubular adenocarcinoma. ${ }^{54}$ These tumours demonstrated reduced size, invasion and lymph node metastasis compared with other less well differentiated tumours, and were described as "less malignant". They were only identified on the basis of cellular atypism and it is possible that other authors may have classified these tumours as benign. This potential discrepancy in classification is important to recognise when comparing incidence and survival rates between countries.

\section{LYMPH NODE INVASION}

Despite only minor local invasion in EGC (by definition) lymph node invasion is still relatively common, with rates varying between 10 and $20 \%$ in most reports (fig 5). The presence of nodal metastases is very closely related to depth of local invasion (fig 6). With submucosal invasion, lymph nodes are involved in between 15 and $30 \%$, but with mucosal lesions, lymph node involvement is much less common $(0-7 \%)$. Furthermore, lymph node invasion is commoner with larger tumours, ${ }^{5446495376}$ and possibly with

TABLE 1 Histological classification of early gastric cancer in the fapanese literature

\begin{tabular}{|c|c|c|c|c|c|c|c|c|c|}
\hline \multirow[b]{2}{*}{ Reference } & \multirow[b]{2}{*}{$\begin{array}{l}\text { Cases } \\
(\mathrm{No})\end{array}$} & \multicolumn{4}{|l|}{ Differentiated } & \multicolumn{3}{|c|}{ Undifferentiated } & \multirow[b]{2}{*}{$\begin{array}{l}\text { Mucinous } \\
\text { adenocarcinoma }\end{array}$} \\
\hline & & $\begin{array}{l}\text { Papillary } \\
\text { adenocarcinoma }\end{array}$ & $\begin{array}{l}\text { Tubular } \\
\text { adenocarcinoma } \\
\text { (well differentiated) }\end{array}$ & $\begin{array}{l}\text { Tubular } \\
\text { adenocarcinoma } \\
\text { (moderately } \\
\text { differentiated) }\end{array}$ & Total & $\begin{array}{l}\text { Poorly } \\
\text { differentiated } \\
\text { type }\end{array}$ & $\begin{array}{l}\text { Signet } \\
\text { ring cell } \\
\text { carcinoma }\end{array}$ & Total & \\
\hline Ohta $e t a l^{44}$ & 984 & - & - & - & 47.7 & - & - & 52.3 & - \\
\hline Xuan $e t a l^{48}$ & 2846 & 1 & 46 & 17 & 64 & 30 & 5 & 35 & 1 \\
\hline Maehara et a $\bar{l}^{0}$ & 423 & - & - & - & 61.7 & - & - & 37.8 & - \\
\hline Endo et $a \bar{P}^{3}$ & 332 & 4.8 & 36.1 & 19.9 & 60.8 & 19.3 & 19.9 & 39.2 & - \\
\hline Itoh $e t a \bar{P}^{5}$ & 109 & 1.8 & 60.6 & - & 62.4 & 29.4 & 7.3 & 36.7 & 0.9 \\
\hline Okuda et $a l^{48}$ & 1019 & 5.7 & 37.2 & 13.8 & 56.7 & 23.5 & 18.6 & 42.1 & 1.2 \\
\hline
\end{tabular}

Values represent per cent of cases. Cancer (per cent of patients with specified symptom). 
poorly differentiated tumours, ${ }^{34}$ although this relation is reported less consistently.

In all but one series, ${ }^{9}$ where lymph node staging is reported the majority (more than $70 \%$ ) of lymph nodes involved are $\mathrm{N} 1$. The rest are usually $\mathrm{N} 2$, but on a few occasions more distant involvement of $\mathrm{N} 3$, and rarely $\mathrm{N} 4$, nodes has been reported. ${ }^{44558}$ This is only seen in the Japanese literature, but is probably owing to the more extensive surgical resection and the meticulous examination of the postoperative specimen.

\section{DISTANT METASTASES}

Liver/haematogenous metastases are rare at the time of diagnosis of EGC, and were reported in only two of the case series reviewed. ${ }^{6268}$ Although this may be biased owing to the reporting of potentially curative surgery alone, it is consistent with the high postoperative survival rates and the benign nature of this disease.

\section{SYNCHRONOUS CANCERS}

The concept of multiple synchronous gastric cancers is well recognised. The criteria for diagnosis was first established by Moertel et al in $1957^{81}$ : (a) each lesion must be of pathologically proven malignancy; $(b)$ all lesions must be distinctly separated by intervals of microscopically normal gastric wall; and (c) the possibility that a lesion represents local extension or metastasis must be ruled out beyond any reasonable doubt.

When reported, the prevalence of synchronous cancers is between 2 and $14 \%$ in European literature (apart from Gardiner et al who amazingly found 14 of 30 EGC to be multifocal ${ }^{15}$ ). This closely echoes the Japanese experience of $5-13 \%$. In addition to double tumours, triple and quadruple tumours have also been reported. ${ }^{345282}$ Synchronous
EGC, however, do not differ from their solitary counterparts with regard to pathological features. ${ }^{51}$

It has been found that the frequency of multiple tumours is commoner in EGC than $\mathrm{AGC},{ }^{23}{ }^{82}$ and this has been taken to imply that progressive carcinoma represents convergence of multiple primary foci. Furthermore, many synchronous tumours are only detected at the time of operation. Noguchi et al reported successful preoperative diagnosis of synchronous microcarcinoma in only $35 \%$ of those cases in which they were eventually demonstrated after resection. ${ }^{51}$ This implies that even careful endoscopic examination of the stomach misses large numbers of small EGC, an important point when the efficacy of screening is considered.

It has been suggested that patients with EGC are predisposed to developing cancer at other sites. Although this may be true for patients with cancer as a rule, there is no compelling evidence that EGC behaves differently from other tumours in this respect. Notwithstanding this, the presence of multiple synchronous tumours suggests that EGC represents a field change of the gastric mucosa as a whole, indicating a high risk of developing further tumours in the rest of the stomach.

\section{Clinical features}

AGE AND SEX DISTRIBUTION

As in AGC, there is a strong male predominance in EGC. In the European literature the male:female ratio varies from 1 to $4.75 .{ }^{1526}$ Sex ratio was stated in 24 European case reports: of 1730 cases in these reports, there was a mean male:female ratio of 1.66 . In the Japanese literature, the male:female ratio was reported in five series, totalling 21590 cases, with a mean of 1.97 . This is only slightly

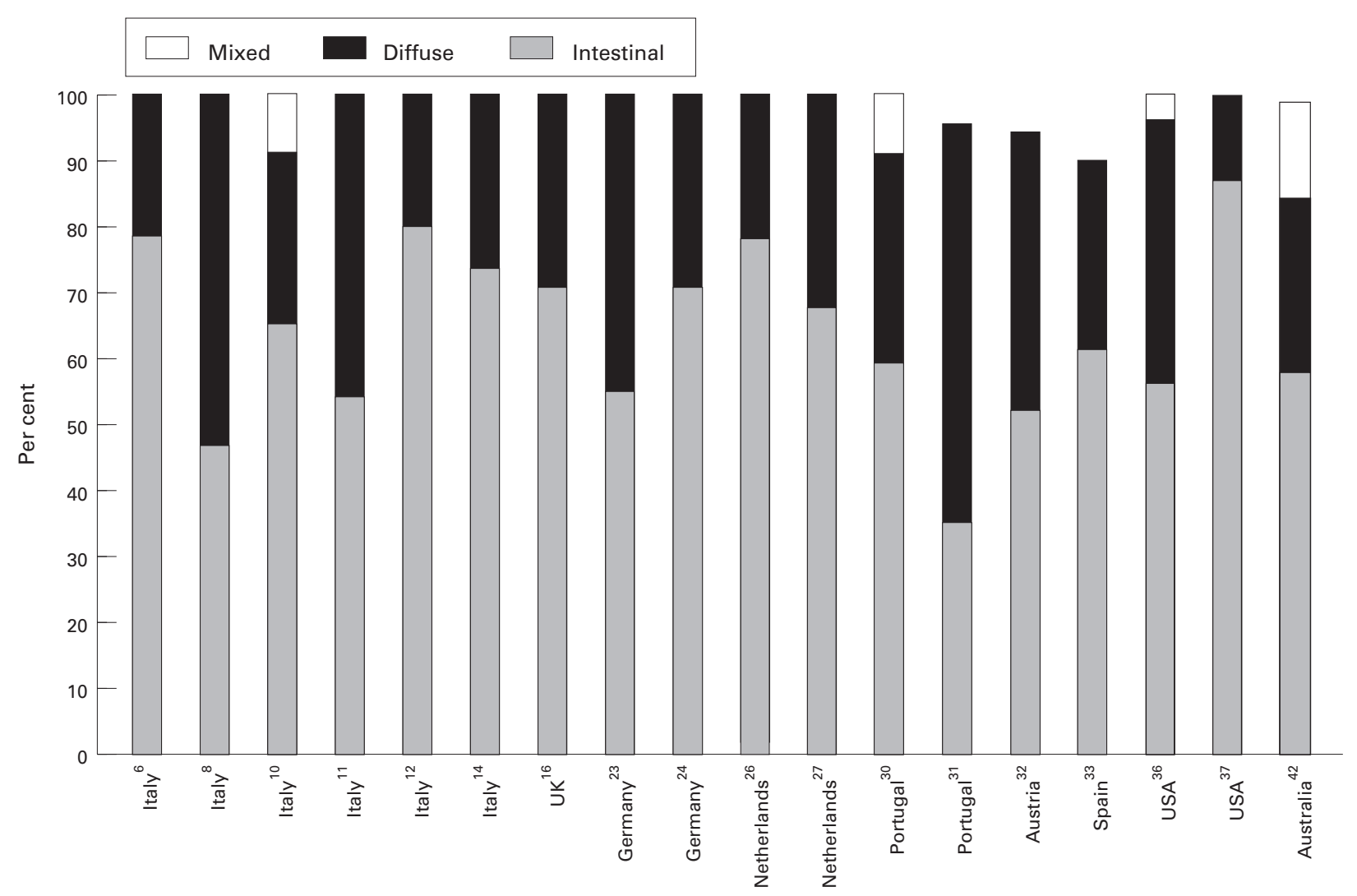

Case series: country and reference

Figure 4: Early gastric cancer according to the Lauren classification: per cent of cases with intestinal, diffuse, or mixed histology. 


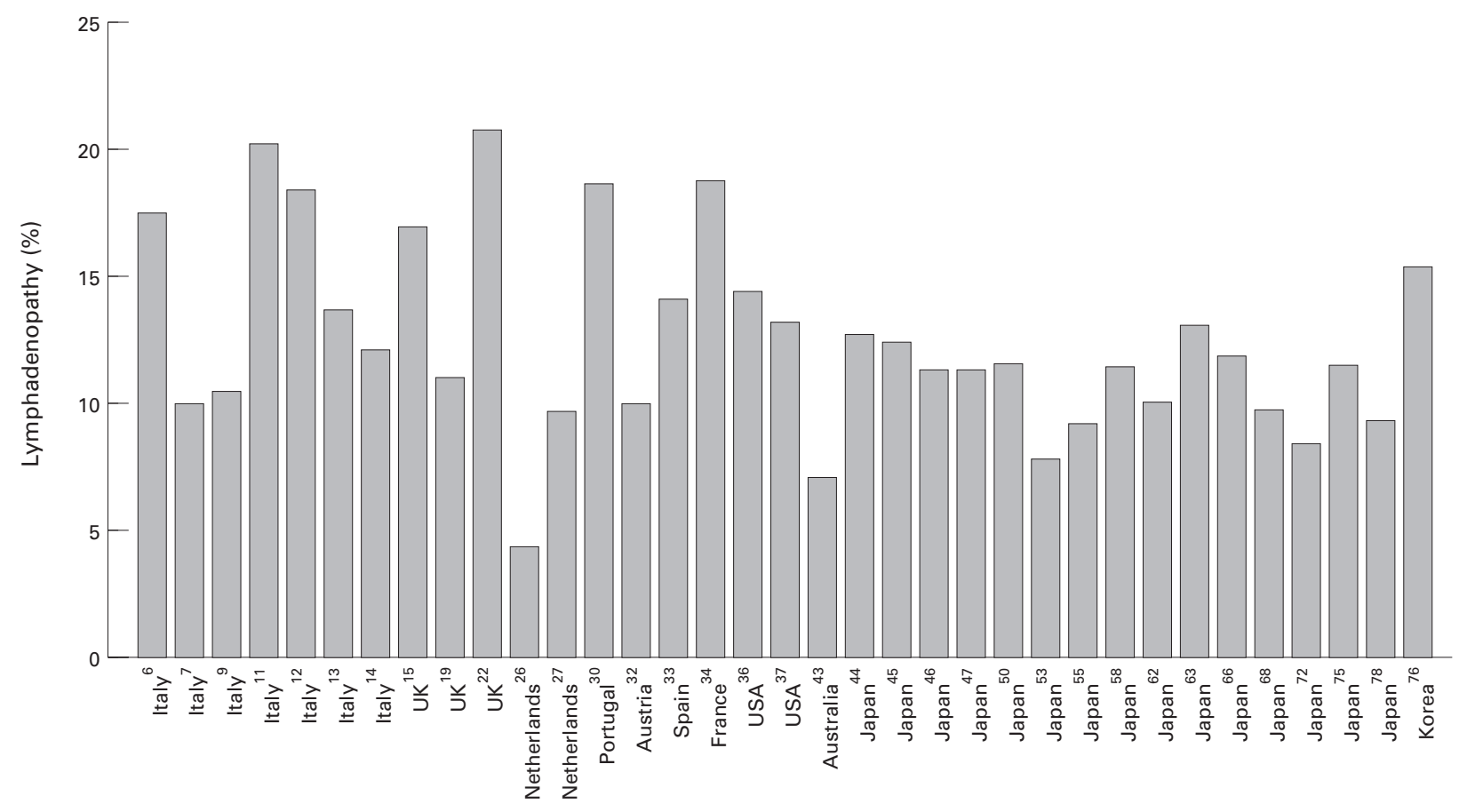

Case series: country and reference

Figure 5: Lymphadenopathy in early gastric cancer: per cent of cases with involved lymph nodes detected at time of operation.

higher than the European mean, but may reflect higher screening rates of the working male population in Japan.

The mean age of patients with EGC was stated in 17 European reports, totalling 1147 cases. Taken together, this gives a mean age of 59.9 years. This is only marginally older than the mean age in Japan (57.8 years; 3378 cases; three case reports); a surprising finding if one considers their screening programme. EGC probably occurs in younger adults than AGC; two series report a difference of eight years, ${ }^{83}$ a third of 23 years (though only five cases of EGC), ${ }^{35}$ whereas a fourth found no difference. ${ }^{6}$

\section{SYMPTOMS}

Owing to the screening of an asymptomatic population, there is little information on the symptoms of EGC in Japan. In Europe the duration of symptoms in EGC is varied but often long. Usually symptoms have been present for longer than six months, ${ }^{18} 27$ and often the mean duration of symptoms is longer than a year. ${ }^{16172643}$ When compared with AGC, the time scale of symptoms in EGC is considerably longer. ${ }^{635}$ In addition, it has been reported that EGC carries a longer prodrome of symptoms if it is ulcerated, rather than protuberant. ${ }^{16}$

The presenting symptoms of EGC resemble those of benign gastric ulcer. ${ }^{23}$ Epigastric pain and dyspepsia are very frequently present (between 60 and 90\%). Anaemia is uncommon at presentation, and history of gastrointestinal bleeding is usually present in less than $25 \%$. Weight loss almost always occurs in less than $40 \%$ of patients (table 2). ${ }^{69192327343637}$ In contrast, weight loss is a common, prominent feature of AGC, occurring in about $60 \%$ of patients. ${ }^{83}$

It is difficult to interpret the observation that the EGC symptom profile and duration more closely resemble benign gastric ulceration than advanced cancer. It may suggest either that EGC can exist undetected in the stomach, causing mild symptoms only for long periods of time, or that there is a gradual malignant conversion of benign disease over such a period. Nevertheless, this similarity in clinical features, taken with the notion that these ulcers can undergo a healing phase, ${ }^{77}$ strengthens the need for aggressive, early investigation of older patients with ulcer-like symptoms.

\section{Treatment of EGC}

In general, the most widely and successfully performed operation for EGC is gastrectomy (distal, proximal or total) with radical R2 lymphadenectomy. This is universal in Japan, but has gained increasing acceptance in Europe in recent years. ${ }^{19}$ Operative mortality is low in Japan, generally less than $1 \%$, compared with a more variable picture in Europe (between 1 and $6.5 \%{ }^{19}{ }^{34}$ ).

Ironically, although European surgeons have gradually been adopting the more aggressive Japanese methods, the Japanese have simultaneously been concentrating on more conservative surgery. Endoscopic mucosal resection (EMR) was introduced in 1978. It is a relatively simple technique that permits en bloc removal of the tumour. In Japan it is now considered for use in patients with (i) differentiated, elevated type less than $2.0 \mathrm{~cm}$ in diameter, (ii) differentiated, depressed type without ulceration, less than $1.0 \mathrm{~cm}$ in diameter, and (iii) the undifferentiated, depressed type without ulcer formation, $0.5 \mathrm{~cm}$ in diameter. ${ }^{58}$

At the Cancer Institute of Tokyo ${ }^{58}$ the use of EMR has been increasing slowly: between 1988 and 1990 it was performed in $23.6 \%$ of all early cancers, with a five year survival of $86 \%$. There are theoretical risks, however, in this approach. Firstly, EGC is frequently associated with synchronous tumours that are not detected during endoscopic examination, and would therefore not be removed at the time of EMR. Secondly, even if there are no synchronous cancers, the remaining stomach is likely to contain areas of premalignant change, such as intestinal metaplasia or dysplasia, that would confer a high risk of carcinoma in the future. Thirdly, it is difficult to be sure of the depth of invasion preoperatively, even with endoscopic ultrasound, ${ }^{84}$ making it extremely difficult to exclude confidently node metastasis preoperatively. 


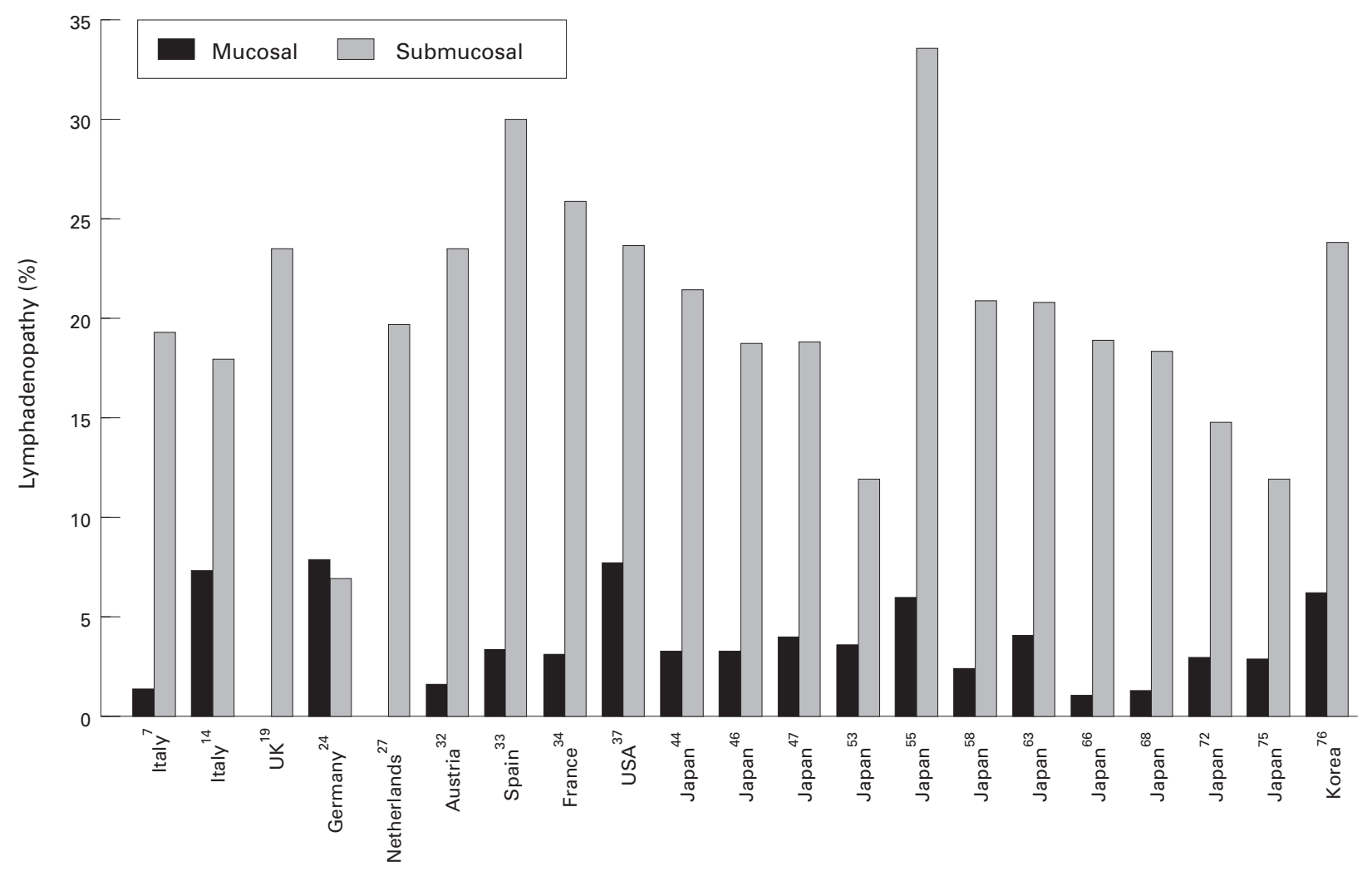

Case series: country and reference

Figure 6: Lymphadenopathy in early gastric cancer according to depth of invasion: per cent of cases with involved lymph nodes detected at time of operation, divided into cases of mucosal invasion alone and cases in which the submucosa has been invaded.

\section{Survival and prognosis}

SURVIVAL

The prognosis for early gastric cancer is universally excellent. Almost all Western and Japanese authors are now reporting five year survival rates of over $90 \%$ for EGC if relative survival or deaths from gastric carcinoma alone are considered. A small number of series has reported survival rates at 10, 15, and 20 years. The Japanese have demonstrated high relative survival to 10 and 15 years, comparable with the rest of the population. ${ }^{6085}$ However, if deaths from other causes are excluded, then the survival is lower after 10 years in Western reports, falling to between 84 and $92 \% .{ }^{112}{ }^{1736}$ In one long term French follow up study, the 15 and 20 year survival rates fell to $58 \%$ and $51 \%$, respectively. This included all cause mortality, though, and is consequently difficult to interpret. ${ }^{34}$

Looking at the recurrence rate of EGC after surgery, the Japanese consistently report a rate of less than $5 \%$. Rates are generally higher in Western reports, usually between 5 and
$15 \%$, with rates of less than $5 \%$ only being found in a handful of cases (fig 7). ${ }^{61219263338}$ While different recurrence rates should be compared with caution, as they are dependent on length of follow up, if they are taken in conjunction with the survival rates it becomes apparent that EGC carries a marginally poorer prognosis in the Western population.

\section{PROGNOSTIC FACTORS}

Figure 8 shows the five year survival of early gastric cancer, divided into those with nodal metastasis and those without. It is not surprising that patients who are free of nodal metastases fare better than those with lymphadenopathy. Furthermore, the prognosis of carcinomas confined to the mucosa is consistently better than those that invade the submucosa (fig 9). This survival advantage is maintained to at least 10 years. ${ }^{1134953556465}$ It seems possible, however, that depth of invasion is not an independent prognostic factor but merely acts as a marker for those patients at higher risk of lymph node invasion.

TABLE 2 Symptom distribution in early gastric cancer (per cent of patients with specified symptom)

\begin{tabular}{|c|c|c|c|c|c|c|c|c|}
\hline Reference & Cases (No) & $\begin{array}{l}\text { Epigastric } \\
\text { pain/dyspepsia }\end{array}$ & Anorexia & Weight loss & $\begin{array}{l}\text { Gastrointestinal } \\
\text { bleeding }\end{array}$ & Anaemia & Nausea/vomiting & None \\
\hline Pinto et al & 142 & 91.2 & - & 42.3 & - & - & 40.1 & - \\
\hline Belcastro et $a l^{9}$ & 19 & 84.2 & 5.3 & 5.3 & - & 5.3 & - & 5.3 \\
\hline Gozzetti et $a l^{14}$ & 49 & 82.6 & - & - & - & - & - & - \\
\hline Houghton $e t a l^{17}$ & 35 & 74 & 23 & 63 & 37 & 14 & 26 & - \\
\hline Ballantyne $e t a l^{18}$ & 20 & 75 & - & - & 15 & 15 & 25 & - \\
\hline Sue-Ling et $a l^{19}$ & 46 & 73 & 18 & 24 & 11 & - & 49 & 9 \\
\hline Eckardt $e t a l^{3}$ & 51 & 70 & 12 & 25 & 8 & - & 11 & - \\
\hline Craanen et $a l^{2^{7}}$ & 28 & 67.8 & - & 10.7 & 25 & - & 17.9 & - \\
\hline Oleagoita $e t a l^{33}$ & 142 & 75.3 & - & - & 5 & - & 6.4 & 4.2 \\
\hline Moreaux et $a b^{34}$ & 101 & 84.2 & - & 3.9 & 6 & 1 & - & 5.9 \\
\hline Carter et $a l^{35}$ & 5 & 80 & - & 40 & - & - & 20 & - \\
\hline Farley et $a l^{36}$ & 48 & 62.5 & 39.6 & 39.6 & 25 & - & 39.6 & - \\
\hline Lawrence $e t a l^{37}$ & 60 & - & - & 21.7 & 21.6 & - & - & - \\
\hline Chia $e t a l^{43}$ & 52 & 67.3 & - & - & 19 & 11.5 & 23.1 & - \\
\hline
\end{tabular}




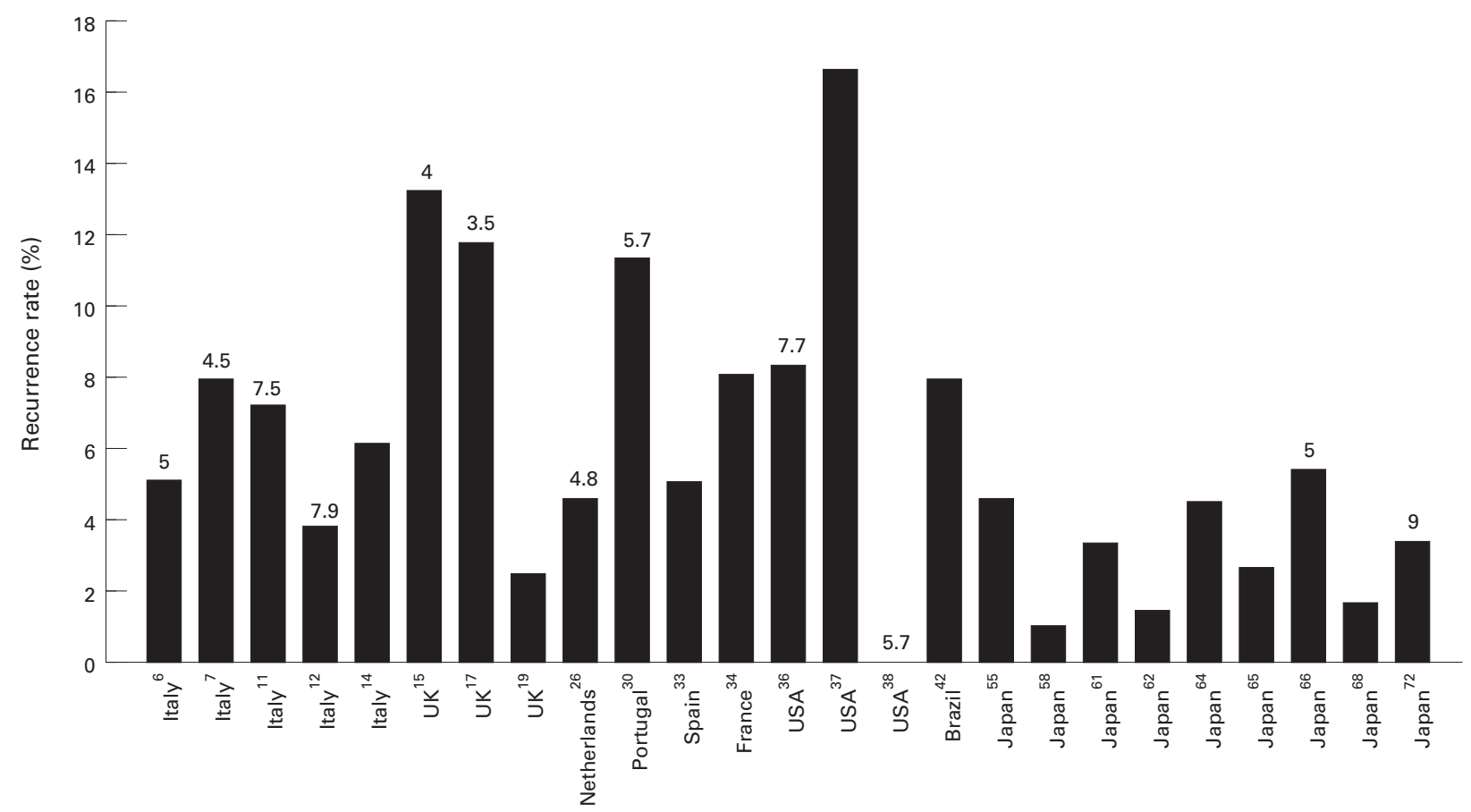

Case series: country and reference

Figure 7: Recurrence rate of early gastric cancer. The recurrence rate was calculated from data published in the relevant references. It includes patients with recurrence of early gastric cancer regardless of ultimate survival. Operative mortality is excluded. Numbers above columns represent follow up in years (mean or median, as reported in the publication).

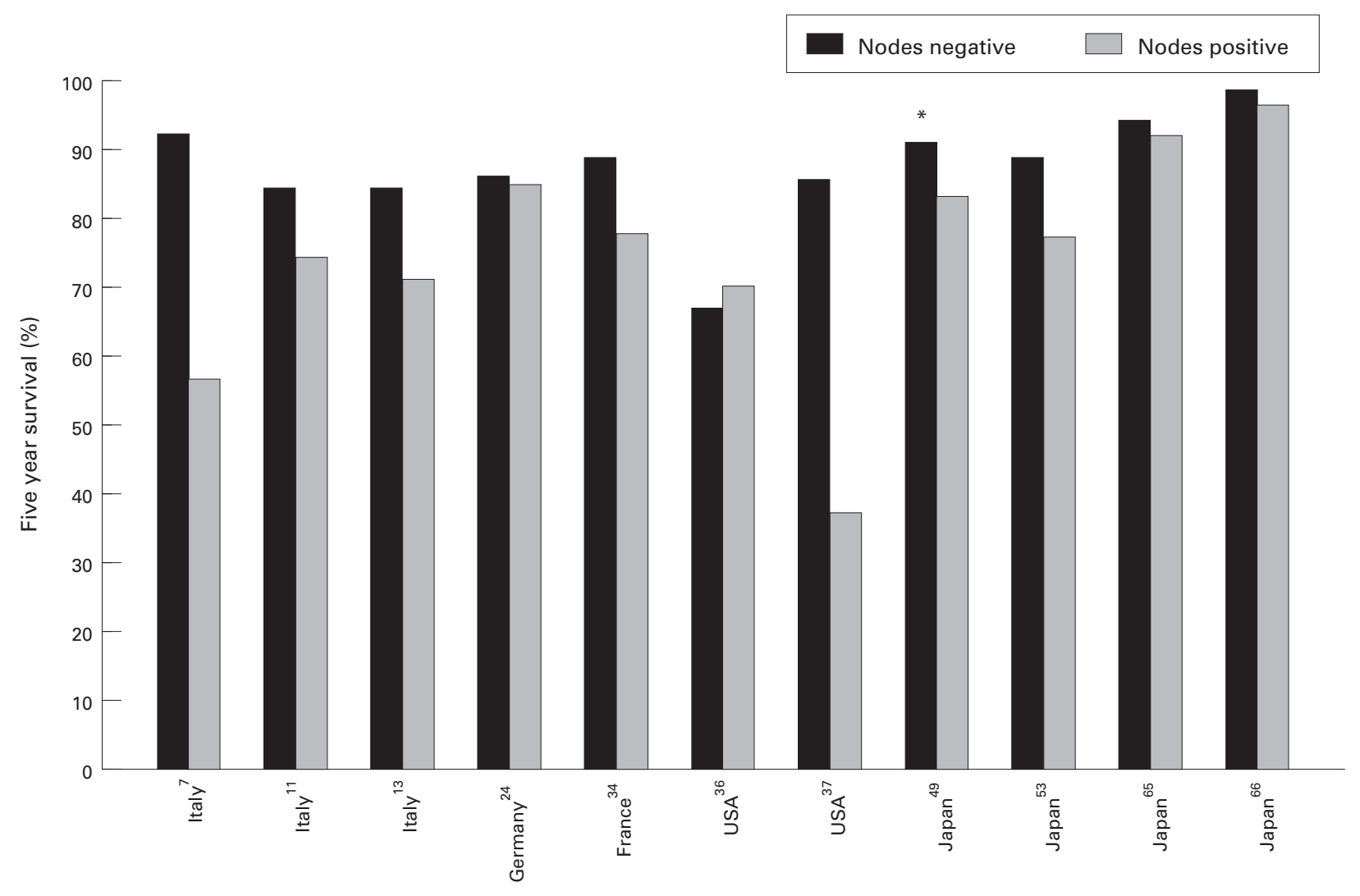

Case series: country and reference

Figure 8: Five year survival of patients with early gastric cancer: prognosis according to presence or absence of lymphadenopathy at time of operation. ${ }^{\star}$ Ten year survival. 


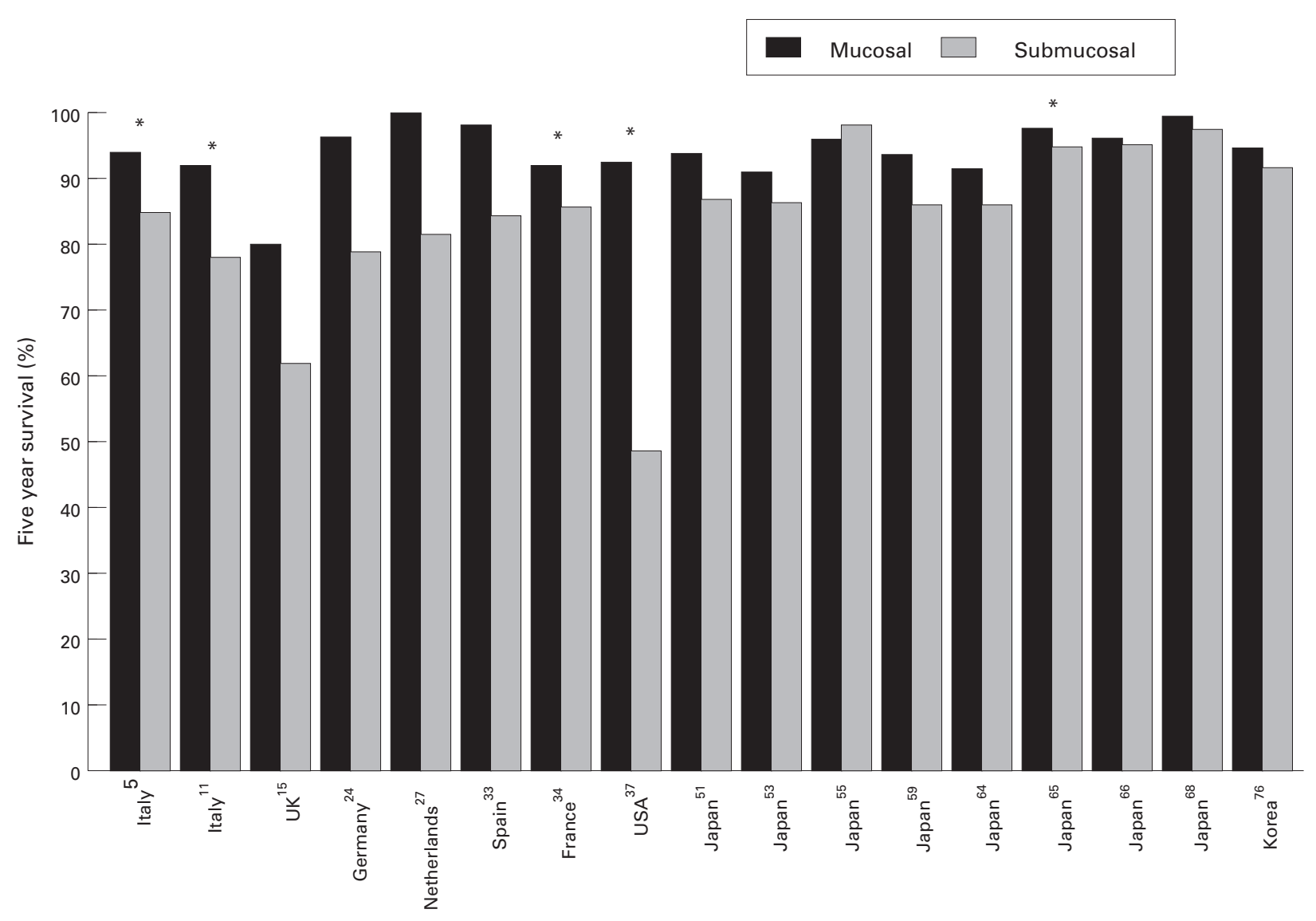

Case series: country and reference

Figure 9: Five year survival of patients with early gastric cancer: prognosis to depth of invasion (mucosal or submucosal) at time of operation. ${ }^{\star} p<0.05$.

Information on other prognostic factors is more variable. Degree of differentiation has been found to either have no prognostic influence ${ }^{1233343769}$ or, where a difference is detected, the differentiated/intestinal types have shown worse prognosis. ${ }^{101124273650566162646768}$ Although this is a consistent finding, it contradicts the observation that less differentiated tumours are associated with deeper invasion and lymph node invasion. Old age seems to confer worse prognosis, ${ }^{113650}$ even after multivariate analysis. ${ }^{67}$ Larger tumour size has been associated with either no difference ${ }^{534}$ or with worse survival rates, ${ }^{3765}$ and excavated/depressed tumours have been associated with a better prognosis. ${ }^{2433} 395667$

\section{Summary}

Despite mass population screening and an incidence of EGC in Japan that is at least double that of the West, there seem to be no genuine differences in the clinicopathological features of the disease between the two regions. The macroscopic appearance, size, depth of invasion, frequency of lymph node invasion, and histology of EGC are all remarkably similar in Japan, Europe and America, as are sex and age distributions.

Patients with EGC are a number of years younger than those with advanced cancer. This is not surprising: Tsukuma et al followed 56 cases of EGC that were not surgically treated and estimated that the median "duration of EGC" before becoming advanced was 37 months. ${ }^{87}$ This suggests that EGC undergoes a period of slow growth before becoming advanced. Further differences between early and advanced cancers include a higher frequency of synchronous cancers and a longer symptom duration in EGC.
Unfavourable prognostic factors in EGC include lymph node invasion, and invasion through the muscularis mucosae, though it is not clear whether these are independent. Repeated attempts have been made to identify other prognostic factors, but no clear pattern has emerged, with the possible exceptions of patient age, tumour size, and the presence of ulceration.

The postsurgical outcome of EGC in the West is marginally less favourable than in Japan. In view of the similar clinical and pathological features in the two regions it seems likely, therefore, that this is because of the more aggressive surgical techniques traditionally used in Japan. Conversely, however, EMR has recently emerged as an important technique in Japan. Despite the advantages of low operative mortality and normal function of the postoperative stomach, there are also a number of potential disadvantages. It would seem sensible, therefore, to await the results of long term follow up studies before widespread adoption of EMR in Europe. Nevertheless, this technique should be considered for frail patients unfit for more radical surgery.

S M EVERETT A T R AXON

The Centre for Digestive Diseases, Gastroenterology Unit, The General Infirmary at Leeds, Great George Street, Leeds LS1 3EX, UK

Correspondence to: Professor A T R Axon.

1 Murakami T. Pathomorphological diagnosis. Definition and gross classification of early gastric cancer. Gann Monogr Cancer Res 1971; 11: 53-5.

2 Saeki J. Uber die histologische prognostic des magenkazinomas. Mitteil Med Gessellsch Tokyo 1938; 52: 191.

3 Llorens P. Gastric cancer mass survey in Chile. Semin Surg Oncol 1991; 7: 339-43.

4 Pisani P, Oliver WE, Parkin DM, Alvarez N, Vivas J. Case-control study of gastric cancer screening in Venezuela. Br F Cancer 1994; 69: 1102-5. 
5 Perri F, Iuliano R, Valente G, et al. Minute and small early gastric cancers in Western population: a clinicopathologic study. Gastrointest Endosc 1995; 41: $475-80$.

6 Biasco G, Paganelli GM, Azzaroni D, et al. Early gastric cancer in Italy. Clinical and pathological observations on 80 cases. Dig Dis Sci 1987; 32: $113-20$

7 Pinto E, Roviello F, de Stefano A, Vindigni C. Early gastric cancer: report on 142 patients observed over 13 years. Fpn f Clin Oncol 1994; 24: 12-9.

8 Leocata P, Gallo P, Chiominto A, et al. Is early gastric cancer, diffuse type, a forerunner of advanced gastric cancer? Tumori 1993; 79: 108-11.

9 Belcastro G, Ferri M, Chiavellati L, Nicolanti V, Schillaci A. Early gastric cancer. Ital F Surg Sci 1988; 18: 3: 227-32.

10 Ferrari M, Ghislandi E, Landonio G, Majno M, Porretta T, Scanzi F. Histology as a prognostic factor in early gastric cancer. Tumori 1992; 78 $181-4$.

11 Guadagni S, Reed PI, Johnston BJ, et al. Early gastric cancer: follow-up after gastrectomy in 159 patients. Br f Surg 1993; 80: 325-8.

12 Percivale $\mathrm{P}$, Bertoglio S, Muggianu M, et al. Long-term postoperative results in 54 cases of early gastric cancer: the choice of surgical procedure. Eur $\mathcal{F}$ Surg Oncol 1989; 15:436-40.

13 Santoro E, Garofalo A, Scutari F, Zanarini T, Carlini M, Santoro E Jr. Early gastric cancer: total gastrectomy vs. distal resection. Results of a study of 271 cases. Hepatogastroenterology 1991; 38: 427-9.

14 Gozzetti G, Mattioli S, Gaudio M, et al. Surgical therapy in "early gastric cancer". Ital f Surg Sci 1987; 17: 225-31.

15 Gardiner KR, Wilkinson AJ, Sloan JM. Early gastric cancer: a report of 30 cases. F R Coll Surg Edinb 1990; 35: 237-9.

16 Evans DMD, Craven JL, Murphy F, Cleary BK. Comparison of 'early gastric cancer' in Britain and Japan. Gut 1978; 19: 1-9.

17 Houghton WJ, Mortensen NJMcC, Allan A, Williamson RCN, Davies JD. Early gastric cancer: the case for long term surveillance. $B M \mathcal{F} 1985 ; 291$ : 305-8.

18 Ballantyne KC, Morris DL, Jones JA, Gregson RH, Hardcastle JD. Accuracy of identification of early gastric cancer. Brf F Surg 1987; 74: $618-9$

19 Sue-Ling HM, Martin I, Griffith J, et al. Early gastric cancer: 46 cases treated in one surgical department. Gut 1992; 33: 1318-22.

20 Fielding JWL, Ellis DJ, Jones BG, et al. Natural history of "early" gastric cancer: results of a 10-year regional survey. $B M F$ 1980; 281:

21 Machado G, Davies JD, Tudway AJC, Salmon PR, Read AE. Superficial carcinoma of the stomach. $B M \mathcal{F} 1976 ; 2: 77-9$

22 Rokkas T, Filipe MI, Sladen GE. Detection of an increased incidence of early gastric cancer in patients with intestinal metaplasia type III who are closely followed up. Gut 1991; 32: 1110-3.

23 Eckardt VF, Giebler W, Kanzler G, Remmele W, Bernhard G. Clinical and morphological characteristics of early gastric cancer. A case-control study. Gastroenterology 1990; 98: 708-14.

24 Gentsch HH, Groitl H, Giedl J. Results of surgical treatment of early gastric cancer in 113 patients. World $\mathcal{F}$ Surg $1981 ; 5: 103-7$

25 Elster K, Kolaczek F, Shimamoto K, Freitag H. Early gastric cancerexperience in Germany. Endoscopy 1975; 7: 5-10.

26 Heesakkers JPFA, Gouma DJ, Thunnissen FBJM, Bemelmans MHA, von Meyenfeldt MF. Non-radical therapy for early gastric cancer. Br f Surg

27 Craanen ME, Dekker W, Ferwerda J, Blok P, Tytgat GNJ. Early gastric cancer: a clinicopathologic study. F Clin Gastroenterol 1991; 13: 274-83.

28 Spataro V, Pedrinis E, Müller W. Descriptive epidemiology of early and advanced gastric cancer in Ticino, Switzerland, with emphasis on time trends. Annals of Oncology 1994; 5: 954-6.

29 Öhman U, Emas S, Rubio C. Relation between early and advanced gastric cancer. Am f Surg 1980; 140: 351-5.

30 Oliveira P, Nobre-Leitao C, Chaves P. Early gastric cancer: an analysis of 44 cases with emphasis on the prognostic significance of the macroscopic and microscopic growth patterns. F Surg Oncol 1992; 51: 118-21.

31 Pereira Coutinho A, Turpin S, Batista C, Ramos M, Quina M. Early gastric cancer. Eur 7 Cancer Prev 1994; 3 (suppl 2): 113.

32 Marczell AP, Rosen HR, Hentschel E. Diagnosis and tactical approach to surgery for early gastric carcinoma: a retrospective analysis of the past 16 years in an Austrian general hospital. Gastroenterologica faponica 1989; 24: $732-6$.

33 Oleagoitia JM, Echevarria A, Santidrian JI, Ulacia MA, Hernandez-Calvo J. Early gastric cancer. Br F Surg 1986; 73: 804-6.

34 Moreaux J, Bougaran J. Early gastric cancer. A 25 year surgical experience. Ann Surg 1993; 217: 347-55.

35 Carter KJ, Schaffer HA, Ritchie WP. Early gastric cancer. Ann Surg 1984; 199: $604-9$.

36 Farley DR, Donohue JH, Nagorney DM, Carpenter HA, Katzmann JA, Ilstrup DM. Early gastric cancer. Br f Surg 1992; 79: 539-42.

37 Lawrence M, Shiu MH. Early gastric cancer. Twenty-eight year experience. Ann Surg 1991; 213: 327-34.

38 Bringaze III WL, Chappuis CW, Cohn I Jr, Correa P. Early gastric cancer. 21 year experience. Ann Surg 1986; 204: 103-7.

39 Green PHR, O'Toole KM, Slonim D, Wang T, Weg A. Increasing incidence and excellent survival of patients with early gastric cancer: experience in a United States medical center. Am F Med 1988; 85: 658-61.

40 Green PHR, O'Toole KM, Weinberg LM, Goldfarb JP. Early gastric cancer. Gastroenterology 1981; 81: 247-56.

41 Hampson LG, Shennib H, Lough JO, Fried GM. Early gastric cancer: is it a distinct clinical entity? Can f Surg 1990; 33: 349-52.

42 Paulino F, Roselli A. Early gastric cancer: report of twenty-five cases. Surgery 1979; 85: 171-6.

43 Chia MM, Langman JM, Hecker R, Lew WYC, Rowland R, Fock KM. Early gastric cancer: 52 cases of combined experience of two south Australian teaching hospitals. Pathology 1988; 20: 216-26.

44 Ohta H, Noguchi Y, Takagi K, Nishi M, Kajitani T, Kato Y. Early gastric arcinoma with special reference to macroscopic classification. Cancer 1987; 60: 1099-106.

45 Tanaka T, Takeda J, Koufuji K, Hashimoto K, Kakegawa T. Early gastric cancer with juxta regional lymph node metastases. Kurume Medical fournal 1991; 38: 287-90.

46 Baba H, Maehara Y, Okuyama T, et al. Lymph node metastasis and macroscopic features in early gastric cancer. Hepatogastroenterology 1994; 41: $380-3$.
47 Fukutomi H, Sakita T. Analysis of early gastric cancer cases collected from major hospitals and institutes in Japan. Ұpn f Clin Oncol 1984; 14: 169-79. 48 Xuan $Z$, Ueyama T, Yao T, Tsuneyoshi M. Time trends of early gastric carcinoma. A clinicopathological analysis of 2846 cases. Cancer 1993; 72:

49 Maehara Y, Orita H, Okuyama T, et al. Predictors of lymph node metastasis in early gastric cancer. Br F Surg 1992; 79: 245-7.

50 Maehara Y, Okuyama T, Oshiro T, et al. Early carcinoma of the stomach. Surg Gynecol Obstet 1993; 177: 593-7.

51 Noguchi Y, Ohta H, Takagi K, et al. Synchronous multiple early gastric carcinoma: a study of 178 cases. World f Surg 1985; 9: 786-93.

52 Brandt D, Muramatsu Y, Ushio K, et al. Synchronous early gastric cancer. Radiology 1989; 173: 649-52.

53 Endo M, Habu $\mathrm{H}$. Clinical studies of early gastric cancer. Hepatogastroenterology 1990; 37: 408-10.

54 Fujii T, Yoshida S, Abe K, et al. "Very well differentiated tubular adenocarcinoma" of the stomach: its endoscopic and histopathological characteristics. Fpn f Clin Oncol 1994; 24: 128-34.

55 Itoh H, Oohata Y, Nakamura K, Nagata T, Mibu R, Nakayama F. Complete ten-year postgastrectomy follow-up of early gastric cancer. Am F Surg 1989;

56 Okuda H, Suzuki S, Suzuki H, et al. Diagnosis and prognosis of early gastric cancer: the experience in Japan. Trop Gastroenterol 1988; 9: 7-13.

57 Shimizu S, Tada M, Kawai. Early gastric cancer: its surveillance and natural course. Endoscopy 1995; 27: 27-31

58 Nishi M, Ishihara S, Nakajima T, Ohta K, Ohyama S, Ohta H. Chronological changes of characteristics of early gastric cancer and therapy: experience in the Cancer Institute Hospital of Tokyo, 1950-1994. F Cancer Res Clin Oncol 1995; 121: 535-41.

59 Iriyama K, Suzuki H. The incidence of early gastric cancer continues to increase in our surgical unit. Int Surg 1992; 77: 41-3.

60 Yamazaki H, Oshima A, Murakami R, Endoh S, Ubukata T. A long-term follow-up study of patients with gastric cancer detected by mass screening. Cancer 1989; 63: 613-7.

61 Matsusaka T, Kodama Y, Soejima K, et al. Recurrence in early gastric cancer. A pathologic evaluation. Cancer 1980; 46: 168-72.

62 Sano T, Sasako M, Kinoshita T, Maruyama K. Recurrence of early gastric cancer. Follow-up of 1475 patients and review of the Japanese literature. Cancer 1993; 72: 3174-8.

63 Okamura T, Tsujitani S, Korenaga D, et al. Lymphadenectomy for cure in patients with early gastric cancer and lymph node metastasis. Am f Surg

64 Koga S, Kaibara N, Tamura H, Nishidoi H, Kimura O. Cause of late postoperative death in patients with early gastric cancer with special reference to recurrence and the incidence of metachronous primary cancer in other organs. Surgery 1984; 96: 511-6.

65 Shiozawa N, Kodama M, Chida T, Arakawa A, Tur GE, Koyama K. Recurrent death among early gastric cancer patients: 20-years' experience. Hepatogastroenterology $1994 ; 41: 244-7$,

66 Fujita Y, Nishioka B, Sakita M, et al. Conservative surgery for regional lymphadenectomy in the treatment of early gastric carcinoma. Fpn f Surg 1983; 13: $184-90$.

67 Moriguchi S, Odaka T, Hayashi Y, et al. Death due to recurrence following curative resection of early gastric cancer depends on age of the patient. $\mathrm{Br}$ Cancer 1991; 64: 555-8.

68 Orita I, Matsusaka T, Wakasugi K, et al. Clinicopathologic evaluation of recurrence in early gastric cancer. $\mathscr{F}$ p $\mathcal{F}$ Surg 1992; 22: 19-23.

69 Ikeda Y, Haraguchi Y, Mori M, et al. Gastric cancer in a general hospital in Japan. Semin Surg Oncol 1994; 10: 150-5.

70 Mori M, Enjoji M, Sugimachi K. Histopathologic features of minute and small human gastric adenocarcinomas. Arch Pathol Lab Med 1989; 113: 926-31.

71 Mori M, Adachi Y, Kakeji K, et al. Superficial flat-type early carcinoma of the stomach. Cancer 1992; 69: 306-13.

72 Ichiyoshi Y, Toda T, Minamisono Y, Nagasaki S, Yakeishi Y, Sugimachi K. Recurrence in early gastric cancer. Surgery 1990; 107: 489-95.

73 Kodama Y, Inokuchi K, Soejima K, Matsusaka T, Okamura T. Growth patterns and prognosis in early gastric carcinoma. Cancer 1983; 51: 320-6.

74 Kodama Y, Inokuchi K, Kamegawa T, et al. Growth patterns of gastric carcinoma detected by mass survey. Fpn f Surg 1984; 14: 366-70.

75 Kidokoro T. Frequency of resection, metastasis and five-year survival rate of Fonn Mogr Cancer Res 1971; 11: 45-9.

$76 \mathrm{Kim}$ J-P, Hur YS, Yang H-K. Lymph node metastasis as a significantly prognostic factor in early gastric cancer: analysis of 1,136 early gastric cancers. Ann Surg Oncol 1995; 2: 308-13.

77 Sakita T, Oguro Y, Takasu S, et al. Observations of the healing of ulcerations in early gastric cancer. Gastroenterology 1971; 60: 835-44.

78 Nagata T, Ikeda M, Nakayama F. Changing state of gastric cancer in Japan. Histologic perspective of the past 76 years. Am f Surg 1983; 145: 226-33.

79 Lauren P. The two histological main types of gastric carcinoma: diffuse and so-called intestinal-type carcinoma. Acta Pathol Microbiol Scand 1965; 64: 31-49.

80 The Japanese Research Society Committee on Histological Classification of Gastric Cancer. The general rules for the gastric cancer study in surgery and pathology. Fpn F Surg 1981; 11: 140-5.

81 Moertel CG, Bargen JA, Soule EH. Multiple gastric cancers. Review of the literature and study of 42 cases. Gastroenterology 1957; 32: 1095-103.

82 Marrano D, Viti G, Grigioni W, Marra A. Synchronous and metachronous cancer of the stomach. Eur F Surg Oncol 1987; 13: 493-8.

83 Wanebo HJ, Kennedy BJ, Chmiel J, Steele G Jr, Winchester D, Osteen R. Cancer of the stomach. A patient care study by the American College of Surgeons. Ann Surg 1993; 218: 583-92.

84 Kodama I, Machi J, Tanaka M, et al. The value of operative ultrasonography in diagnosing tumor extension of carcinoma in the stomach. Surg Gynecol Obstet 1992; 174: 479-84.

85 Kaneko E, Nakamura T, Umeda N, Fujino M, Niwa H. Outcome of gastric carcinoma detected by gastric mass survey in Japan. Gut 1977; 18: 626-30. 86 Hisamichi S, Sugawara N. Mass screening for gastric cancer by x-ray examination. fpn f Clin Oncol 1984; 14: 211-23.

87 Tsukuma H, Mishima T, Oshima A. Prospective study of "early" gastric cancer. Int $\mathcal{F}$ Cancer 1983; 31: 421-6.

88 Shiratori Y, Nakagawa S, Kikuchi A, et al. Significance of a gastric mass screening survey. Am f Gastroenterol 1985; 80: 831-4. 